\title{
Social status influences microhabitat selection: breeder and floater Eagle Owls Bubo bubo use different post sites
}

\author{
LETIZIA CAMPIONI, ${ }^{1 *}$ MARÍA D. M. DELGADO ${ }^{1,2}$ \& VINCENZO PENTERIANI ${ }^{1,3}$ \\ ${ }^{1}$ Department of Conservation Biology, Estación Biológica de Doñana, C.S.I.C., c/Americo Vespucio s/n, \\ 41092 Seville, Spain \\ ${ }^{2}$ Department of Biological and Environmental Sciences, Laboratory of Ecological and Evolutionary Dynamics, \\ University of Helsinki, FI-00014 Helsinki, Finland \\ ${ }^{3}$ Finnish Museum of Natural History, Zoological Museum, University of Helsinki, FI-00014 Helsinki, Finland
}

\begin{abstract}
Social status can be reflected in many aspects of an individual's behaviour and ecology, including habitat use and conspecific interactions. In territorial species where at least two social groups - breeding birds and non-territorial floaters - are recognized, the diverse tasks associated with territorial ownership can lead territory holders to behave differently from the non-territorial part of the population. Territory holders defend their breeding area and reproduce, whereas floating individuals are dispersing and lead a more transient life, during which they do not show any territorial behaviour even when settling in a more or less fixed area (known as the stop phase). As social interactions are based on visual and vocal cues, the use of specific sites for sending and/or receiving signals can be a crucial choice in an animal's life. By analysing the post-site selection of Eagle Owl Bubo bubo breeders and floaters during their nocturnal activity, we found that: (1) territory holders selected more visible and dominant posts than non-territorial floaters; (2) the choice of posts made by floating individuals did not differ between the wandering and stop phases of dispersal; and (3) floating females intruded more frequently than floating males within a breeder's home-range. These findings highlight the fact that two social strategies are possible within the same species, depending on an individual's social status and its related tasks. Breeders could take advantage of visible locations to declare their status as territory holders, whereas floaters could benefit from a more secretive life to wander unnoticed among occupied territories. This secretive life would help floaters to reduce the risks associated with conspecific aggression. Finally, the greater occurrence of floating females within breeders' home-ranges can be explained by the fact that female incursions in a breeder's home-range are less risky than male intrusions.
\end{abstract}

Keywords: conspecific interactions, dispersal, post-site selection, territorial intrusions, territory holders.

From a behavioural perspective, social status is assumed to lead to variation in animal behaviour (Smith 1978, King 1980, Rohner 1997, King \& Allainé 2002, McGowan et al. 2006, Fero et al. 2007, Hojesjo et al. 2007). Specifically, in territorial species where at least two social groups -

*Corresponding author.

Email: letizia@ebd.csic.es breeders and non-territorial floaters - are recognized, territorial ownership can lead to holders behaving differently from the floating counterpart of the population (Jamieson \& Zwickel 1983, Arcese 1987, Zach \& Stutchbury 1992, Rohner 1997, Stamps \& Krishnan 1998). Additionally, social status can be reflected in many aspects of an individual's behaviour and ecology, including habitat use, interactions with conspecifics or willingness 
to take risks (Robitaille \& Prescott 1983, Gese \& Ruff 1998, Fero et al. 2007, Herberholz et al. 2007). Several behavioural traits have been described in detail for territorial individuals of many species (Hojesjo et al. 2007, Afonso et al. 2008, Kinahan \& Pillay 2008), whereas behaviours of the less detectable and frequently overlooked floating contingent of animal populations remain largely unexplored (Penteriani \& Delgado 2009a). In birds, for instance, there are few studies that have been able to record and quantify floaters' behaviour (Smith 1978, Stutchbury \& Robertson 1987, Stutchbury 1991, Rohner 1997). Moreover, studies including both floaters and breeders have mainly focused on investigating mechanisms of territory acquisition or understanding fundamental ecological dynamics at the population level (e.g. Hamilton \& May 1977, Johnson \& Gaines 1990, Whitlock 2001, Penteriani et al. 2005a,b, 2006, 2008a,b). However, and perhaps due to the difficulties related to data collection on floaters, differences in behavioural strategies due to their different social status still need to be understood in greater depth. Knowledge of the behavioural tactics and role of floaters in a population is essential to the understanding of the evolution of animal behaviour under the social constraints determined by differences in social status.

The social context of territorial breeders is generally characterized by long-lasting stable interactions (e.g. territorial displays) among territorial neighbours. Floaters are mainly dispersing individuals that lead a more wandering life and do not show any territorial behaviour even when settling in a more or less fixed area (e.g. Rohner 1997). Indeed, during their more nomadic life, non-breeders encounter new social and physical environments that may affect their behaviour at different spatial and temporal scales during the different phases of dispersal (Smith 1978, Foster 1987, Arcese 1989, Stutchbury 1991, Tobler \& Smith 2004, Aragón et al. 2006, Delgado \& Penteriani 2008, Delgado et al. 2009). Nevertheless, peculiar social interactions also exist among breeders and floaters, mainly when both these portions of a population share the same space at the same time. Evidence exists that floaters are like a 'shadow population', living close to territory holders or sharing portions of their home-ranges with them (Jamieson \& Zwickel 1983, Arcese 1987, Walls \& Kenward 1995, 1998, Rohner 1997). When floaters are close to or within the territory of a breeder, they can be very secretive because holders are typically aggressive towards floaters (Arcese 1987). The sites used by birds for specific activities represent focal points, both within home-ranges and in the routine movements of breeders and floaters, and could potentially represent a key element of individual behavioural strategies, especially when individuals with different social status move within the same areas.

Territory holders and non-territorial floaters of Eagle Owls Bubo bubo share (to some extent) the same areas. Both social groups present similarities in the use of habitat-elements, i.e. they both use distinct post sites to perform routine activities. For instance, being 'sit and wait' predators, owls use perch-sites during nocturnal hunting sessions where they can spend several hours (Penteriani et al. 2008c). Breeding owls select precise plucking and defecation sites within their nesting sites (Penteriani \& Delgado 2009b,c), territory holders repeatedly use call-posts during vocal and visual communication (Delgado \& Penteriani 2007, Penteriani et al. 2007a,b) and breeders and floaters tend to be faithful to the same diurnal roosting sites when ending their nocturnal activities (Delgado et al. 2009). This evidence allows us to hypothesize that, depending on their different social status and the diverse tasks associated with it, the tradeoff between costs and benefits that influence behavioural decisions of individuals of different social classes may produce divergent behavioural strategies. The strategy of breeders is primarily aimed at maintaining the holding of resources and mates. The floaters' strategy is principally aimed at searching for an empty breeding site while reducing the risks associated with conspecific aggression due to visible intrusions. In species such as raptors, contests between conspecifics can end up in wasteful and potentially injurious fights. As a result, we should expect that internal (i.e. social status) and external (i.e. environmental features such as social context) factors might interact in a divergent way when determining the behavioural choices of these two distinct social statuses.

Very few studies have attempted to determine the potential effect of social status on the behavioural process of habitat selection (but see Brown \& Long 2007). This information is even scarcer when considering species that not only show elusive behaviour due to their status of floaters but also because of their nocturnal activity. Here, we analysed the post-site selection of 
both breeder and floater Eagle Owls. Floating Eagle Owls go through a multiphase natal dispersal process characterized by an intense exploratory stage (the wandering phase) followed by the establishment of one or more temporary settlement areas (the stop phase; Delgado \& Penteriani 2008). During such phases, floating individuals may live very close to the breeding portion of the population and share large portions of their home-ranges with breeders (Rohner 1997). Moreover, in the stop phase, floaters can show welldefined home-ranges quite similar to those of territory holders (Delgado et al. 2009). In contrast to territorial conspecifics, they behave as elusive individuals that do not declare their presence. In fact, they have never been observed displaying territorial behaviours in any areas of their range (Delgado 2008, Delgado et al. 2009). Breeders maintain their territory year-round and over several years, having well-defined home-ranges with internal core areas (e.g. nest territory, hunting areas) of intense use (Delgado \& Penteriani 2007). As previously stated, owls show a clear preference for exposed locations during many intra-specific communication activities. Therefore, we specifically focus on several features characterizing the dominance and the visibility of post sites to determine the degree of selection performed by individuals of each social status.

If post-site selection constitutes a relevant aspect of social status-dependent strategies, three predictions can be made. First, we expect that territory holders and non-territorial floaters will select post sites with different visibility. Given the behavioural dependency of territorial individuals on vocal and visual communication, we expect a disproportionate selection of dominantly located posts by breeders relative to non-breeding individuals. Secondly, due to their lack of territorial behaviour and their main need to remain hidden from breeders during dispersal, we can consequently expect that floaters will always select post sites with similar characteristics of visibility, independent of their phase of dispersal. In fact, male territory holders are very aggressive, mainly towards male intruders, and such attacks frequently end with the death of one of the opponents (see also Penteriani et al. 2007a for more details on intra- and inter-sexual contests). For this reason, our final expectation was that floating females will be found more frequently in a breeder's home-range than will floating males.

\section{METHODS}

\section{Study area and data collection}

The study site was a hilly area of the Sierra Norte of Seville (Sierra Morena massif) located in southwestern Spain (for more details, see Penteriani et al. 2005c).

To compare perching behaviours of breeders and floaters, we used information from 39 radiotagged individuals: two females and 13 males from 15 different breeding sites, and 24 floaters (nine females and 15 males). Juveniles were radiotagged at the nest when they were approximately 35 days old, 5-10 days prior to the onset of fledging. Breeding Owls were captured by simulating a territorial intrusion with a combination of a taxidermic mount of an Eagle Owl and a net (Penteriani et al. 2007a). Owlets were aged following Penteriani et al. (2005c) and were sexed by molecular procedures using DNA extracted from blood (Griffiths et al. 1998). Both adults and young were fitted with a teflon ribbon backpack harness that carried a 30-g radio-transmitter (Biotrack Ltd, Wareham, Dorset, UK), with a mercury posture sensor that allowed us to discriminate perching behaviour from periods of activity (e.g. vocal display, hunting or flying) by changes in the radio signal of the transmitters. When the tag pulse increased its frequency and its volume changed, we assumed that the Owl was shifting from a vertical and fixed position (i.e. perched individual) to a horizontal and dynamic position (i.e. flying individual). The change in volume was due to the variation of the distance between the individual and the car antenna because of the individual's movement (Penteriani et al. 2008c). Furthermore, vocal and hunting activities, while perching (i.e. at constant pulse volume), produced iterative changes of the tag pulse due to repeated movements of the Owl's body, which allowed us to discriminate Owl behaviour while perching (Penteriani et al. 2008c). As the young were still growing, the backpacks were adjusted so that the teflon ribbon could expand (Delgado \& Penteriani 2007). The manipulation was always safe: after 7 years of continuous radiotracking of both breeders and floaters, we never recorded a potential adverse effect of backpacks on birds or breeding performance (Delgado \& Penteriani unpubl. data). The backpacks were not removed after the study due to the difficulty in retrapping the same individual (Penteriani \& 
Delgado unpubl. data). Owls were trapped and marked under the Junta de Andalucía - Consejería de Medio Ambiente permit nos. SCFFSAFR/GGG RS-260/02 and SCFFS-AFR/CMM RS-1904 /02.

Locations of radio-marked animals were determined by triangulations using three-element hand-held Yagi antennas (Biotrack) with Stabo (XR-100) portable ICOM receivers (IC-R20). We performed continuous radiotracking year-round following a single Owl during the whole night from $1 \mathrm{~h}$ before sunset to $1 \mathrm{~h}$ after sunrise. Juveniles were followed from the beginning of natal dispersal (end of August in our study area, Delgado \& Penteriani 2008) until either death of the animal or failure of the battery transmitter $(\sim 1.5$ to $\sim 2.5$ years); this is across both the wandering and the stop phases.

Triangulations were generally done at a low range of distances (100-300 m), with an accuracy of mean \pm se $=83.5 \pm 49.5 \mathrm{~m}$ (Penteriani \& Delgado 2008). Such a value was calculated when, after a triangulation, we needed to locate the individual exactly to manipulate it during field experiments (e.g. Penteriani et al. 2007b) or to record the cause of mortality if it died.

To determine the beginning and the end of the different phases (i.e. start, wandering and stop phases) of dispersal, we recorded the position of each juvenile weekly, typically when Owls were at their diurnal roost sites. For each individual, we plotted the distances between its natal nest and diurnal roost site for each weekly location and an individual's mean distances of all weekly locations and the natal nest during the entire dispersal period. We considered dispersal to have started when individuals left their parents' home-range (i.e. at the end of August at a mean ( \pm sd) age of $170 \pm 20.51$ days; range: 131-232 days), which we estimated as the point when the distance of each weekly location from the nest becomes larger than the individual's mean distance during the dispersal period (Delgado \& Penteriani 2008). After leaving the natal territories, dispersal distances progressively increased. Finally, when Owls reached the stop phase of dispersal, dispersal distances levelled off. We considered that Owls had settled in a stable settlement area when the distances between successive weekly locations became smaller than the average distance of previous weekly movements calculated for each dispersing Owl separately (for more details see
Delgado \& Penteriani 2008). The transition from the wandering to the stop phase typically occurred in mid March of the following year at a mean ( \pm sd) age of $395 \pm 109.86$ days (range: 181-640 days). Therefore, the wandering phase encompasses the movements between the start of dispersal and the final settlement in a more or less stable area.

Post sites were selected from data collected during 226 nights of radiotracking (132 for breeders and 94 for floaters). To ensure independence between points, for each individual: (1) the whole set of points was placed on a map by GIS software (ArcView 3.2) and a distance of $150 \mathrm{~m}$ between locations was set as the minimum threshold to consider two fixes as two distinct perch sites; (2) in several cases (i.e. sunset, sunrise, moonlight), it was possible to make visual contact with the perched individual and, consequently, to confirm the radiotracking localization; and, when possible, (3) faeces, plucked prey, Owl feathers and/or pellets were used to confirm the exact location of perching posts.

\section{Post-site characteristics}

To analyse the degree of prominence of Owls' posts, we calculated two indices. First, the dominance index was used, which quantifies the domination of a focal point with regard to the surroundings. This index is calculated as the average difference of altitude between the elevation of the post-site location and the elevations at the end of three lines of $100 \mathrm{~m}$ that, starting from the post site, progress in the direction of the main valley, at 45 and at $90^{\circ}$ (Gainzarain et al. 2000, Delgado \& Penteriani 2007). Secondly, the visibility index of the post sites was calculated with regard to the surroundings, i.e. the number of contour lines covered by the diameter of a circle around the post site with a radius of $100 \mathrm{~m}$. The diameter was drawn perpendicular to the general slope of the contour lines surrounding the post site. High values of these two indices indicate increasing dominance and visibility (Gainzarain et al. 2000).

\section{Floater's post-site locations within breeder's home-ranges}

As additional information on the relationships between breeders and floaters, we explored the 
frequencies of male and female floater post sites within the 15 breeder home-ranges. We considered the frequencies of floater roosts inside vs. floater roosts outside breeders' home-ranges (calculated by minimum convex polygon, MCP; Hayne 1949) as an indirect measure of the number of intrusions of each sex in the breeder's home-ranges.

\section{Statistical analysis}

We performed five separate generalized linear mixed models (GLMMs, McCullagh \& Nelder 1989) using SAS macro program GLIMMIX (version 8.2; SAS Institute 2001), which iterates procedure MIXED (PROC MIXED in sAS software). Degrees of freedom have been computed by using the containment method, i.e. the PROC MIXED default method when one or more random statements are used to specify the variancecovariance structure. The use of the containment method is justified because the design of our matrix is balanced and our random statement has been written so that the relationship between fixed and random effects is clear. We modelled the response variables, dominance index and visibility index, using a Poisson distribution (or a negative binomial distribution when Poisson was not appropriate) with a log link function always including individual identity as a random effect. The dominance index was transformed by adding 30 (the largest negative value) to each value, enabling us to model it with a Poisson distribution. We assessed whether the selection of post sites characterized by different degree of dominance (first model) and visibility (second model) were influenced by social status $(1=$ breeder; $0=$ floater). To avoid the possibility that our results could be biased because floaters select less dominant and visible points as they may occur in areas with less irregular topography (i.e. the selection of posts is the by-product of the general areas where they live), we repeated these two models selecting only those post sites that were located in the areas in which the home-ranges of breeders and floaters overlapped (i.e. the habitat structure was equal for both social groups). The third and fourth models assessed the effect of the dispersal stage (indexed as 1 for wandering and 0 for stop phases) as a categorical (explanatory) variable on the floater post-site selection, again with dominance and visibility indices as the response variables. In all these models, we initially considered sex as a further potential factor affecting the selection of post sites. As its effect was never significant (always $P>0.10$ ), we removed this factor from the models. Finally, to assess whether the presence of floaters' post sites inside breeders' home-ranges was associated with the sex of floating Owls, we modelled the location of the post site (indexed as 1 for a post inside and 0 for a post outside an adult's home-range) against the sex of the floater, in this case using a binomial error distribution. The significance of all explanatory variables (and their interaction) was tested in turn in the models (stepwise forward procedure), retaining only those that contributed significantly to the change in deviance. Statistical significance was accepted at $\mathrm{P} £ 0.05$.

\section{RESULTS}

\section{Breeders and floaters use different post sites}

A total number of 679 post sites of 15 breeders ( $n=225$ post sites) and 24 floaters ( $n=454$ post sites) were identified. Posts differed significantly between the two social statuses on the basis of the dominance $\left(\mathrm{F}_{1,643}=5.73, \mathrm{P}=0.017 ;\right.$ Fig. $\left.1 \mathrm{a}\right)$ and visibility indices $\quad\left(F_{1,643}=20.92, \quad P<0.0001\right.$; Fig. 1b). That is, breeders (visibility range: $0-10$, median $=3$; dominance index range: 30-90, median $=38$ ) preferred dominant posts, whereas floaters mainly selected hidden locations (see Fig. 2 for an example of the three-dimensional spatial distribution of post sites). This happened also when considering only those floater posts ( $n=245$ post sites) that overlapped with the breeder's homeranges, i.e. when taking into account the potential effect of the habitat structure (dominance index: $\mathrm{F}_{1,432}=4.76, \quad \mathrm{P}=0.03$; visibility index: $\mathrm{F}_{1,432}=$ 9.34, $\mathrm{P}=0.0024$; Fig. 3).

\section{Phases of dispersal do not affect floater selection of posts}

When comparing the visual characteristics of 171 posts used during the wandering phase with the features of 199 post locations during the stop phase of 19 floaters that shifted between these phases (a subsample of the whole set of floaters), there was no significant difference in post-site selection (all $\mathrm{P}>0.1$; Fig. 1). 
(a)

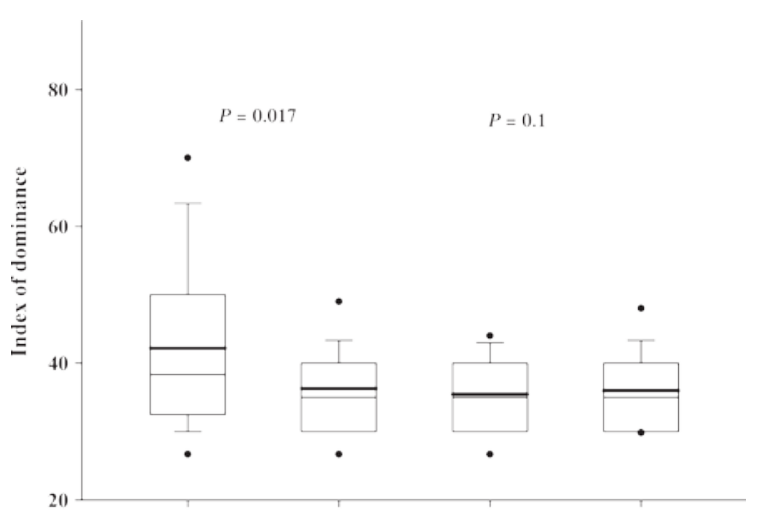

(b)

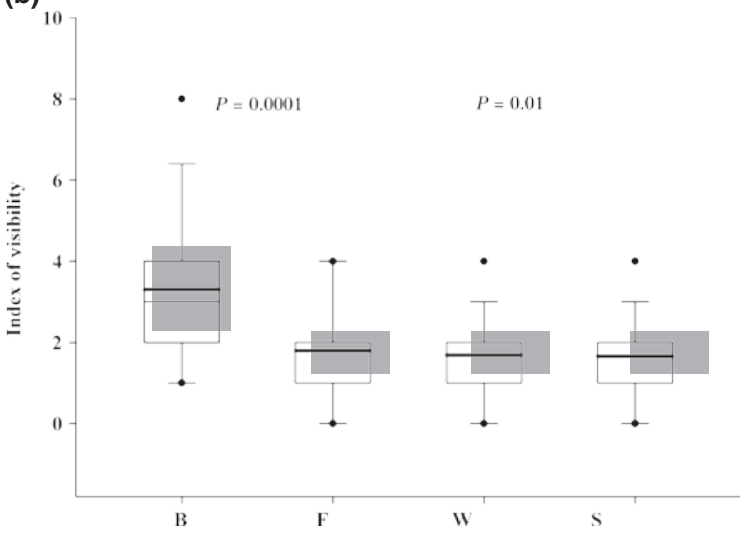

Figure 1. Full dataset box plots of: (a) the degree of dominance of breeders' (B) vs. floaters' (F) post sites, as well as floaters' during the wandering (W) vs. stop (S) phases of dispersal; and (b) the degree of visibility of breeders' (B) vs. floaters' (F) post sites and floaters' post sites during the wandering (W) vs. stop (S) phases of dispersal. For each box plot the total data range, the 25 and $75 \%$ quartiles (box), the mean (bold line) and the median (thin line) are presented. P-values (from GLIMMIX procedure) show the levels of significance of both degree of dominance and visibility for the comparisons between breeders vs. floaters and wandering vs. stop.

\section{Floating females intrude more frequently than males in breeders' home-ranges}

The mean home-range size (MCP 100\%) of floating females $\left(\bar{A}_{\mathrm{f}}=769 \pm 187 \mathrm{ha} ; \mathrm{n}=9\right)$ was smaller than the mean home-range of floating males $\left(\bar{A}_{m}=1053 \pm 402\right.$ ha; $\left.n=15\right)$. Nevertheless, floating males intruded less frequently than floating females into the breeders' home-ranges: posts of floating females $(n=172)$ were more frequently (70.3\%) located inside a breeder's home-range than outside $\left(F_{1,430}=5.64, \quad P=0.018\right)$. Con- versely, floating males' post sites $(n=284)$ were less commonly located inside (43\%) a breeder's home-range. Because the home-ranges of floating females is smaller than for floating males, we can exclude the possibility that the recorded differences in locations of male and female floaters inside breeders' home-ranges are dependent on the sex-biased size of the floaters' home-ranges.

\section{DISCUSSION}

Our results highlight how a spatial characteristic of animal habitats, hunting post sites, was selected differently by individuals of the same species depending on their territorial status. Breeders and floaters selected post sites with distinctly different visibility, with the most visible locations occupied by breeders. This implies that individuals of different social status may employ different behavioural strategies, which may produce divergent patterns of habitat use and selection. While breeders can take advantage of visible locations to declare their status as territory owners, floaters can take advantage of secrecy to wander unnoticed among territorial conspecifics during the whole natal dispersal period.

The importance of post sites in territorial behaviour, and their influence on life-history traits, has previously been demonstrated for true shrikes (Laniidae; Yosef 1993, Safriel 1995). Moreover, characteristics such as the height or dominance of post sites have been investigated in relation to vocalizations of breeding individuals (e.g. Marten \& Marler 1977, Simpson 1985, Møller 1988, Mathevon \& Aubin 1997, Beck \& George 2000, Penteriani 2002, Delgado \& Penteriani 2007, Naguib et al. 2008) or to hunting efficiency (Fitzpatrick 1980, Tye 1989, Sonerud 1992, Yosef 1993), providing some evidence for how adaptive behaviour can maximize the transmission of vocal signals and hunting success, respectively (Yosef 1993, 2004). In fact, we cannot ignore the fact that dominance and visibility of post sites can have a relevant function in hunting strategy as well. Being ambush predators, owls can obtain considerable advantages by perching on dominant locations. In fact, it has been shown that for many predator species, such as Hawk Owl Surnia ulula, Common Buzzard Buteo buteo, Rough-legged Buzzard Buteo lagopus and Common Kestrel Falco tinnunculus (Sonerud 1980, 1992), there exists a positive correlation between perching height and the size of 
Figure 2. (a) Spatial distribution of Eagle Owl post sites $(\boldsymbol{\Lambda}=$ floater, $\mathbf{h}=$ breeder) where the home-ranges (MCP 100\%) of both social statuses; one breeding male (grey polygon, period: 2004-2005) and one floating male (in the wandering phase, period: 20052006; black polygon) occurred alongside one another. (b) Enlarged three-dimensional image of a small home-range's section [grey polygon in (a)] shared by the same two individuals, with post-site spatial distributions represented. The territory holder (h) preferentially selected the more dominant and visible locations, whereas the floater $(\boldsymbol{\Delta})$ perched on more hidden posts.

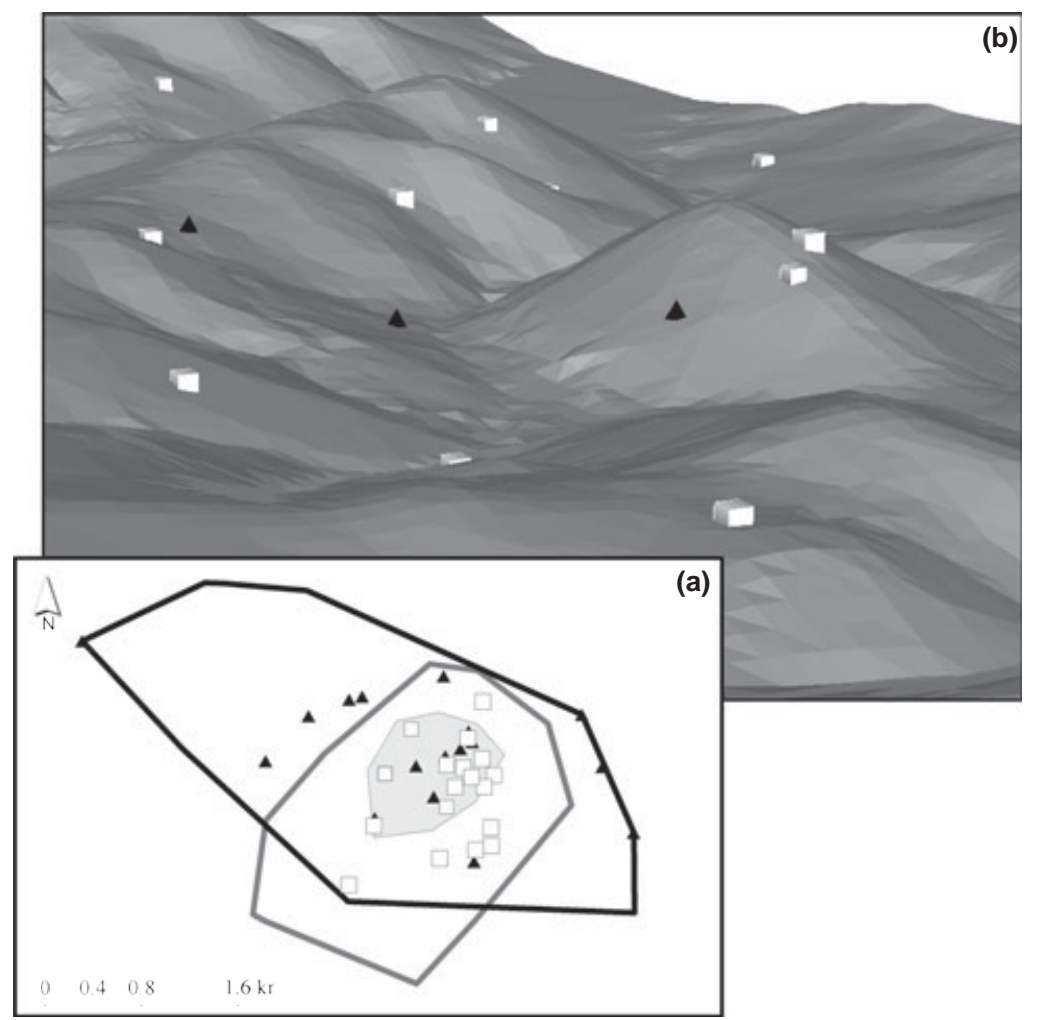

the area that can be searched from a post site. From this perspective, post-site selection could have a function not only in the intra-specific communication but also in the hunting strategy. However, and depending on their main activity (vocalizations vs. hunting), Owl behaviour and localization within dominant posts can be different even when using the same post site (V. Penteriani \& M.M. Delgado unpubl. data): call displays are generally performed from the top of dominant posts (e.g. the pinnacle of a tree canopy), whereas hunting prospection is more frequently done from a more concealed position (e.g. within the tree canopy) and silently.

To our knowledge, no attention has been paid to how the 'visibility' of perching locations relates to the social status of the chooser. Among social species, indirect warning signs used to inform about the occupancy of a territory are, in general, widespread (e.g. scent and faeces marking; Kappeler 1990, Katti 2001, Gese 2001). Such marking behaviours rely strictly on the use of strategic points, i.e. vantage points, visible locations or locations of easy access, where the marks are displayed. A similar behaviour has previously been observed in Eagle Owls during the breeding season, when Owls used either faeces or prey's feathers to mark focal locations of their home-ranges (Penteriani \& Delgado 2009c).

Territorial status incurs a cost to keep the possession of such resources, and breeding Owls are compelled to perform territorial defence and sexual displays to preserve their territory and mate. Under such a scenario, being in a dominant location facilitates both visual and vocal communication with conspecifics by informing the social environment of one's presence. Moreover, in species characterized by aggressive territorial behaviours and weapons, several benefits can be gained by a territory holder selecting dominant and visually connected posts. Holders might avoid being involved in dangerous aggressive encounters with occasional intruders crossing their territorial boundaries because the latter are aware of their presence from afar. This might represent both a safe strategy and a way to reduce wasting time and energy in dangerous contests, which can then be invested in other activities. When floating Owls are crossing and/or sharing the areas occupied by territory holders, breeders' visibility may also be 


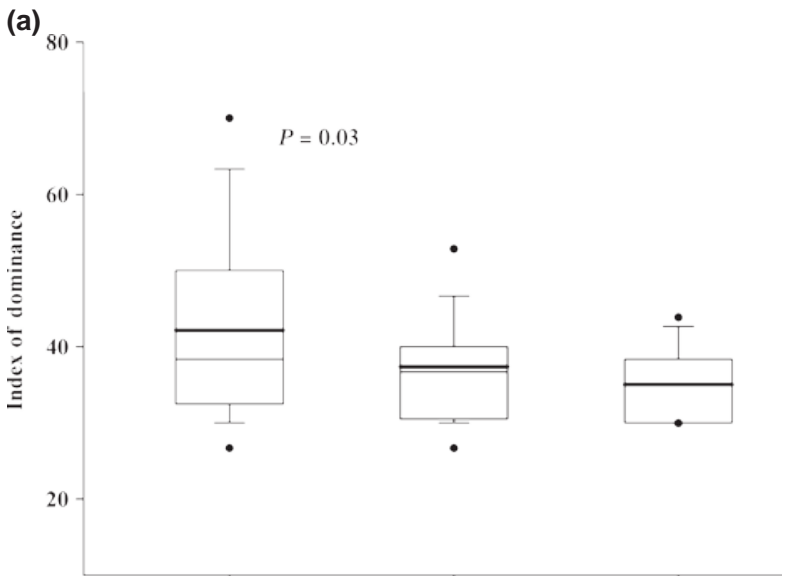

(b)

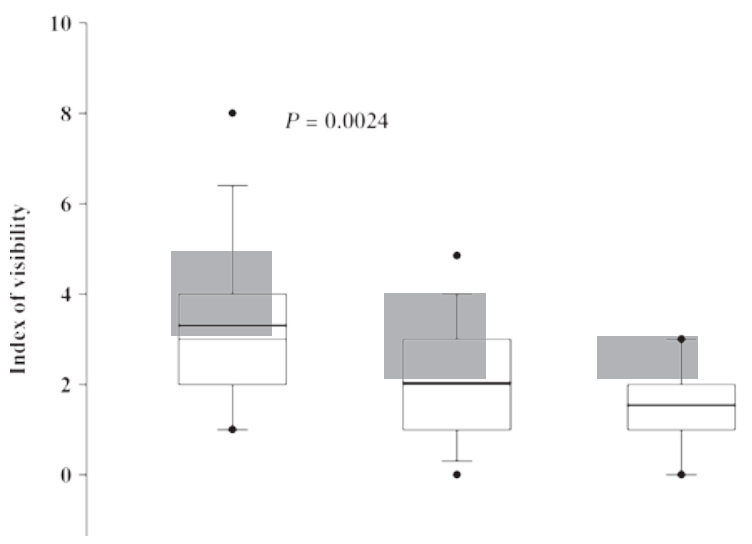

Figure 3. Box plot of (a) the degree of dominance and (b) the degree of visibility of post sites selected by breeders (B), by floaters inside ( $F$ in) and floaters outside ( $F$ out) the homeranges of breeders. For each box plot the total data range, the 25 and $75 \%$ quartiles (box), the mean (bold line) and the median (thin line) are presented. P-values (from the GLIMmIX procedure) show the levels of significance of both degree of dominance and visibility for the comparisons among breeders and floaters inside and outside the breeders' home-ranges.

acting, at least partially, as a signal received by several floating individuals. From the top of their dominant posts, territory holders might be acting as continuous signallers during the entire time spent perching (not only when actively performing vocal/visual displays). The high visibility achieved by such positions may expand the propagation distance of the signal and, as a consequence, increase the number of individuals able to receive the signal. This especially could be true when large numbers of floaters occupy a given area. In the case of the Great Horned Owls Bubo virginianus, for example, they may represent up to $40-50 \%$ of the whole population (Rohner 1996). As floaters in breeding territories are unwanted individuals, they can be considered silent bystanders gathering information on the features of the social environment of the areas they cross during dispersal. Hence, we can hypothesize that the floaters in such a network might be able to obtain useful information just by attending to breeders' communication networks as eavesdroppers (Peake \& McGregor 2005), while avoiding risky contests with holders.

For dispersing floaters that do not need to defend a territory, and whose principal need is the avoidance of aggressive encounters with conspecifics, 'visibility' can result in an increase of fatal aggressive encounters by territorial conspecifics. As Owls may cross several breeding areas of conspecifics during the different phases of dispersal, as well as settle within one of them, it might be advantageous for them to go unnoticed when gathering social and spatial information, while avoiding risky circumstances. The use of less visible post sites by floaters can be explained, at least partially, by the complex array of behavioural patterns that territorial Owls can exhibit, such as site-specific aggressiveness or the ability to discriminate neighbours from intruders (Penteriani et al.

2007a). Moreover, we can hypothesize that the voluntary selection of less dominant and concealed posts may also represent a way to communicate no intention of intrusion if discovered by a territorial individual. Thus, the selection of concealed posts might help floaters reduce the risk of conspecific aggression associated with dispersion. The secretive behaviour of floaters therefore allows them to overlap broadly with defended territories (Rohner 1996). As reported by Rohner (1997), floaters may settle in the interstices between different breeding territories and stay unobtrusively within the home-range of territory holders. However, this secretive behaviour of avoiding less dominant post sites does not imply that these are less efficient hunting posts and that floaters pay a cost. In fact, although both are dominant, optimal hunting and communication post sites differ in their dominance range: a tree or a cliff located on the lowest part of a valley does not represent a dominant point within the neighbours' network (i.e. it is not useful for territoriality), but it is a sufficiently high point to survey a hunting area and detect prey.

Additionally, the different frequencies of occurrence of post sites of male vs. female floating Owls within breeders' home-ranges could be considered 
a consequence of the different intra- and intersexual aggressive behaviours shown by the study species. As shown in Penteriani et al. (2007a), when the territorial intruder is a female, both male and female holders respond weakly or do not react at all. In such a scenario, floating females may be performing less risky intrusions than floating males if perceived by territory holders. Finally, because polygamy can occur in Eagle Owls (Dalbeck et al. 1998, Penteriani \& Delgado unpubl. data), a floating female entering a holder's territory might also represent to a male the possibility of occasionally reproducing with two females.

To conclude, the ultimate patterns encountered for breeder and floater Owls, as well as for male and female floaters, highlight that the social components that characterize the status of individuals cannot be neglected, as they can affect the individual behaviour and, consequently, produce divergent patterns of habitat selection.

For their help with fieldwork we are grateful to P. Bartolommei and C. Maggio. We thank R. Lourenço, R. Nager, D. Serrano, C. Spottiswoode, D.B. Stouffer and an anonymous referee for their helpful comments and improvements of the first draft. Funding for this study was provided by two research projects from the Spanish Ministry of Science and Innovation (CGL2004$02780 / \mathrm{BOS}$ and CGL2008-02871/BOS). During this work L.C. was supported by a doctoral grant from the C.S.I.C., M.M.D. was supported by a doctoral grant from the Spanish Ministry of Science and Innovation and V.P. received a grant from the Spanish Secretaría General de Universidades, Ministry of Education (Salvador de Madariaga Program).

\section{REFERENCES}

Afonso, P., Fontes, J., Holland, K.N. \& Santos, R.S. 2008. Social status determines behaviour and habitat usage in a temperate parrotfish: implications for marine reserve design. Mar. Ecol. Prog. Ser. 359: 215-227.

Aragó n, P., Meylan, S. \& Clobert, J. 2006. Dispersal statusdependent response to the social environment in the Common Lizard, Lacerta vivipara. Funct. Ecol. 20: 900-907.

Arcese, P. 1987. Age, intrusion pressure and defence against floaters by territorial male Song Sparrow. Anim. Behav. 35: 773-784.

Arcese, P. 1989. Territory acquisition and loss in male Song Sparrows. Anim. Behav. 37: 45-55.

Beck, M.J. \& George, T.L. 2000. Song post and foraging site characteristics of breeding varied thrushes in Northwestern California. Condor 102: 93-103.

Brown, D.R. \& Long, J.A. 2007. What is a winter floater? Causes, consequences, and implication for habitat selection. Condor 109: 548-565.
Dalbeck, L., Bergerhausen, W. \& Krishner, O. 1998. Telemetriestudie zur Orts- und Partnertreue beim Uhu Bubo bubo. Vogelwelt 119: 37-344.

Delgado, M.M. 2008. Exploring natal dispersal under the perspective of animal movement analysis. A behavioural study on the dispersal of a long-lived species. PhD Thesis, University of Seville.

Delgado, M.M. \& Penteriani, V. 2007. Vocal behaviour and neighbour spatial arrangement during vocal displays in Eagle Owls. J. Zool. Lond. 271: 3-10.

Delgado, M.M. \& Penteriani, V. 2008. Behavioral states help translate dispersal movements into spatial distribution patterns of floaters. Am. Nat. 172: 475-485.

Delgado, M.M., Penteriani, V., Nams, V.O. \& Campioni, L. 2009. Changes of movement patterns from early dispersal to settlement. Behav. Ecol. Sociobiol. 64: 35-43.

Fero, K., Simon, J.L., Jourdie, V. \& Moore, P.A. 2007. Consequences of social dominance on crayfish resource use. Behaviour 144: 61-82.

Fitzpatrick, J.W. 1980. Foraging behavior of Neotropical Tyrant Flycatchers. Condor 82: 43-57.

Foster, M.S. 1987. Delayed maturation, neoteny, and social system differences in two manakins of the genus Chiroxiphia. Evolution 41: 547-558.

Gainzarain, J.A., Arambarri, R. \& Rodrìguez, A.F. 2000. Breeding density, habitat selection and reproductive rates of the Peregrine Falcon Falco peregrinus in Álava (northern Spain). Bird Study 47: 225-231.

Gese, E.M. 2001. Territorial defence by coyotes (Canis latrans) in Yellowstone National Park, Wyoming: who, how, where, when, and why. Can. J. Zool. 79: 980-987.

Gese, E.M. \& Ruff, R.L. 1998. Howling by coyotes (Canis latrans): variation among social classes, seasons, and pack sizes. Can. J. Zool. 76: 1037-1043.

Griffiths, R., Double, M.C., Orr, K. \& Dawson, R.J.G. 1998. A DNA test to sex most birds. Mol. Ecol. 7: 1071-1075.

Hamilton, W.D. \& May, R.M. 1977. Dispersal in stable habitat. Nature 269: 578-581.

Hayne, D.W. 1949. Calculation of home range size. J. Mammal. 30: 1-18.

Herberholz, J., McCurdy, C. \& Edwards, D.H. 2007. Direct benefits of social dominance in juvenile crayfish. Biol. Bull. 213: 21-27.

Hojesjo, J., Okland, F., Sundstrom, L.F., Pettersson, J. \& Johnsson, J.I. 2007. Movement and home range in relation to dominance; a telemetry study on brown trout Salmo trutta. J. Fish Biol. 70: 257-268.

Jamieson, I.G. \& Zwickel, F.C. 1983. Spatial patterns of yearling male Blue Grouse and their relation to recruitment into the breeding population. Auk 100: 653-657.

Johnson, M.L. \& Gaines, M.S. 1990. Evolution of dispersal: theoretical models and empirical tests using birds and mammals. Annu. Rev. Ecol. Syst. 21: 449-480.

Kappeler, P.M. 1990. Social status and scent-marking behaviour in Lemur catta. Anim. Behav. 40: 774-788.

Katti, M. 2001. Vocal communication and territoriality during the non-breeding season in a migrant warbler. Curr. Sci. 80: 419-423.

Kinahan, A. \& Pillay, N. 2008. Dominance status influences female reproductive strategy in a territorial African rodent Rhabdomys pumilio. Behav. Ecol. Sociobiol. 62: 579587. 
King, B.R. 1980. Social organization and behaviour of the Grey-crowned Babbler Pomatostomus temporalis. Emu 80: 59-76.

King, W.J. \& Allainé, D. 2002. Social, maternal, and environmental influences on reproductive success in female Alpine marmots (Marmota marmota). Can. J. Zool. 80: 21372143.

Marten, K. \& Marler, P. 1977. Sound transmission and its significance for animal vocalization. Behav. Ecol. Sociobiol. 2: 271-290.

Mathevon, N. \& Aubin, T. 1997. Reaction to conspecific degradated song by the Wren Troglodytes troglodytes: territorial response and choice of song post. Behav. Processes 39: 77-84.

McCullagh, P. \& Nelder, J.A. 1989. Generalised Linear Modelling. London: Chapman \& Hall.

McGowan, A., Sharp, S.P., Simeoni, M. \& Hatchwell, B.J. 2006. Competing for position in the communal roosts of Long-tailed Tits. Anim. Behav. 72: 1035-1043.

Møller, A.P. 1988. Spatial and temporal distribution of song in the Yellowhammer Emberiza citrinella. Ethology 78: 321-331.

Naguib, M., Schmidt, R., Sprau, P., Roth, T., Flörcke, C. \& Amrhein, V. 2008. The ecology of vocal signalling: male spacing and communication distance of different song traits in Nightingales. Behav. Ecol. 19: 1034-1040.

Peake, T.M. \& McGregor, P.K. 2005. Animal Communication Networks. Cambridge: Cambridge University Press.

Penteriani, V. 2002. Variation in the function of Eagle Owl vocal behaviour: territorial defence and intra-pair communication? Ethol. Ecol. Evol. 14: 275-281.

Penteriani, V. \& Delgado, M.M. 2008. Brood-switching in Eagle Owl Bubo bubo fledglings. Ibis 150: 816-819.

Penteriani, V. \& Delgado, M.M. 2009a. Thoughts on natal dispersal. J. Raptor Res. 43: 90-98.

Penteriani, V. \& Delgado, M.M. 2009b. The dusk chorus from an owl perspective: Eagle Owls vocalize when their white throat badge contrasts most. PLoS ONE 4: e4960.

Penteriani, V. \& Delgado, M.M. 2009c. Owls may use faeces and prey feathers to signal current reproduction. PLoS ONE 3: e3014.

Penteriani, V., Otalora, F. \& Ferrer, M. 2005a. Environmental stochasticity in dispersal areas can explain the 'mysterious' disappearance of breeding populations. Proc. R. Soc. Lond. B 272: 1265-1269.

Penteriani, V., Otalora, F., Ferrer, M. \& Sergio, F. 2005b. Floater survival affects population persistence. The role of prey availability and environmental stochasticity. Oikos 108: 523-534.

Penteriani, V., Delgado, M.M., Maggio, C., Aradis, A. \& Sergio, F. 2005c. Development of chicks and pre-dispersal behaviour of young in the Eagle Owl Bubo bubo. Ibis 147: 155-168.

Penteriani, V., Otalora, F. \& Ferrer, M. 2006. Floater dynamics can explain positive patterns of density-dependence fecundity in animal populations. Am. Nat. 168: 697-703.

Penteriani, V., Delgado, M.M., Alonso-Alvarez, C. \& Sergio, F. 2007a. The importance of visual cues for nocturnal species: Eagle Owls signal by badge brightness. Behav. Ecol. 18: 143-147.

Penteriani, V., Delgado, M.M., Alonso-Álvarez, C., Viqueira Pina, N., Sergio, F. \& Bartolommei, P. 2007b. The impor- tance of visual cues for nocturnal species: Eagle Owl fledglings signal with white mouth feathers. Ethology 113 : 934-943.

Penteriani, V., Otalora, F. \& Ferrer, M. 2008a. Floater mortality within settlement areas can explain the Allee effect in breeding populations. Ecol. Modell. 213: 98-104.

Penteriani, V., Ferrer, M., Otalora, F. \& Delgado, M.M. 2008b. When individuals senesce: the 'Florida effect' on stable populations of territorial, long-lived birds. Oikos 118 : 321-327.

Penteriani, V., Delgado, M.M., Bartolommei, P., Maggio, C., Alonso-Alvarez, C. \& Holloway, G.J. 2008c. Owls and rabbits: predation against substandard individuals of an easy prey. J. Avian Biol. 39: 215-221.

Robitaille, J.F. \& Prescott, J. 1983. Use of space and activity budgets in relation to age and social status in a captive herd of American bison, Bison bison. Zoo Biol. 12: 367-379.

Rohner, C. 1996. The numerical response of great horned owls to the snowshoe hare cycle: consequences of non-territorial 'floaters' on demography. J. Anim. Ecol. 65: 359-370.

Rohner, C. 1997. Non-territorial 'floaters' in Great Horned Owls: space use during a cyclic peak of snowshoe hares. Anim. Behav. 53: 901-912.

Safriel, U. 1995. What's special about shrikes? Conclusions and recommendations. Proc. West. Found. Vertebr. Zool. 6: 299-308.

SAS Institute 2001. SAS/STAT Software: Changes and Enhancements, Version 8.2. Cary, NC: SAS Publishing.

Simpson, B.S. 1985. Effects of location in territory and distance from neighbours on the use of song repertoires by Carolina Wrens. Anim. Behav. 33: 793-804.

Smith, S.M. 1978. The 'underworld' in a territorial sparrow: adaptive strategy for floaters. Am. Nat. 985: 571-582.

Sonerud, G.A. 1980. Hunting strategies of birds which feed on small mammals in boreal forests (in Norwegian). Cand. Real Thesis, University of Oslo.

Sonerud, G.A. 1992. Search tactics of a pause-travel predator: adaptive adjustments of perching times and move distances by Hawk Owls (Surnia ulula). Behav. Ecol. Sociobiol. 30: 207-217.

Stamps, J.A. \& Krishnan, V.V. 1998. Territory acquisition in lizards. IV. Obtaining high status and exclusive home ranges. Anim. Behav. 55: 461-472.

Stutchbury, B.J. 1991. Floater behaviour and territory acquisition in male Purple Martins. Anim. Behav. 42: 435-443.

Stutchbury, B.J. \& Robertson, R.J. 1987. Behavioral tactics of subadult female floaters in the Tree Swallow. Behav. Ecol. Sociobiol. 20: 413-419.

Tobler, M. \& Smith, H.G. 2004. Specific floater home ranges and prospective behaviour in the European Starling, Sturnus vulgaris. Naturwissenschaften 91: 85-89.

Tye, A. 1989. A model of search for the Northern Wheatear Oenanthe oenanthe and other pause-travel predators. Ethology 83: 1-18.

Walls, S.S. \& Kenward, R.E. 1995. Movements of radiotagged Common Buzzards Buteo buteo in their first year. Ibis 137: 177-182.

Walls, S.S. \& Kenward, R.E. 1998. Movements of radiotagged Buzzards Buteo buteo in early life. Ibis 140: 561568.

Whitlock, M.C. 2001. Dispersal and genetic properties of metapopulations. In Clobert, J., Danchin, E., Dhondt, A.A. 
\& Nichols, J.D. (eds) Dispersal: 273-282. Oxford: Oxford University Press.

Yosef, R. 1993. Influence of observation posts on territory size of Northern Shrikes. Wilson Bull. 105: 180-183.

Yosef, R. 2004. Perch-site use and inter- and intraspecific aggression of migratory Brown Shrikes (Lanius cristatus) in Southern Taiwan. Biol. Lett. 41: 113-118.
Zach, S. \& Stutchbury, B.J. 1992. Delayed breeding in avian social systems: the role of territory quality and 'floater' tactics. Behaviour 123: 194-219. 